CARVACHO, Pablo; VALDÉS, Amalia; MATEO, Mariel: "El derecho a la defensa

penitenciaria en Chile: cuando no hay derecho".

Polít. Crim. Vol. 16, № 31 (Junio 2021), Art. 10, pp. 254-283

[http://politcrim.com/wp-content/uploads/2021/07/Vol16N31A10.pdf]

\title{
El derecho a la defensa penitenciaria en Chile: cuando no hay derecho
}

"The Right to in Prison Defense in Chile: When there is no Right"

\author{
Pablo Carvacho Traverso \\ Magíster en Sociología Pontificia Universidad Católica de Chile \\ Magíster en Ciencias del Derecho U. de Stanford, Estados Unidos \\ Centro de Estudios Justicia y Sociedad, Pontificia Universidad Católica de Chile \\ pacarvac@uc.cl \\ https://orcid.org/0000-0003-3464-945X \\ Amalia Valdés Riesco \\ Magíster en Criminología en U. de Manchester, Inglaterra. \\ Centro de Estudios Justicia y Sociedad, Pontificia Universidad Católica de Chile. \\ $\underline{\text { https://orcid.org/0000-0002-9648-610X }}$ \\ Mariel Mateo Piñones \\ Magíster en Sociología Pontificia Universidad Católica de Chile \\ mdmateo@uc.cl \\ https://orcid.org/0000-0002-9607-7541
}

\section{Resumen}

Fecha de recepción: 01/03/2020.

Fecha de aceptación: 28/08/2020.

La población penal tiene necesidades jurídicas específicas. Mientras varias de estas guardan relación con cuestiones judiciales propias del encierro, otras se vinculan a materias de índole personal. Cualquiera sea la naturaleza de estas necesidades, estas deberían ser atendidas por la defensoría penal penitenciaria, servicio especializado de la Defensoría Penal Pública (DPP). Este artículo presenta algunos de los resultados obtenidos de un extenso trabajo de campo con metodología mixta en cárceles y oficinas de defensa penitenciaria de seis regiones de Chile, en donde se realizaron 766 observaciones no participantes de primeras entrevistas en los penales, 616 análisis de carpetas y del Sistema Informático de Gestión de Defensa Penal (SIGDP), 19 entrevistas a funcionarios de Gendarmería y Defensores penitenciarios, 9 grupos focales con internos e internas de ocho penales, encuesta de validación de resultados a 92 defensores y trabajadores sociales de la defensa penitenciaria del país y panel de expertos, con el fin de proveer una radiografía de la defensa penitenciaria en Chile. Los resultados muestran cómo el ejercicio de la defensa penitenciaria se ve limitada por una serie de factores, pero especialmente por la superposición de culturas, prácticas y normas institucionales diversas. Se afirma que esta situación se mantendrá mientras no exista un derecho penitenciario que regule las expectativas y prácticas institucionales en conflicto. Esta ausencia de derecho, se expone, termina dejando al arbitrio y discrecionalidad de autoridades administrativas la defensa efectiva de los derechos de las personas privadas de libertad. 


\title{
Polít. Crim. Vol. 16, № 31 (Junio 2021), Art. 10, pp. 254-283 [http://politcrim.com/wp-content/uploads/2021/07/Vol16N31A10.pdf]
}

Palabras claves: Defensa penitenciaria, culturas institucionales, derecho penitenciario, cárceles, Gendarmería.

\begin{abstract}
The prison population has specific legal needs. While several of these needs are judicial in nature, others are related to personal issues. Whatever the nature of these needs, they should be addressed by the Penitentiary Public Defender's Office, a specialized service of the Public Defender's Office. This article presents the findings obtained from an extensive fieldwork in prisons and penitentiary defense offices in six Chilean regions, with 766 non-participant observations of first interviews in prisons, 616 analysis of folders and of the Computer System of Criminal Defense Management (SIGDP), 19 interviews with Gendarmerie officials and prison defenders, 9 focus groups with prisoners from eight jails, a survey to validate results with 92 responses of defenders and social workers of the penitentiary offices, and a panel of experts, in order to provide an X-ray of the prison defense in Chile. The results show how the exercise of prison defense is limited by a number of factors, but especially, by the overlap of diverse institutional cultures, practices and norms. It is argued that as long as there is no prison law that regulates conflicting institutional expectations and practices, this problem will continue. The absence of law leaves the effective defense of convicts' rights to the discretion of administrative authorities.
\end{abstract}

Keywords: Penitentiary defense, institutional cultures, prison's law, prisons, Prison's Office.

\section{Introducción}

La población penitenciaria en Chile la componen 42.046 personas privadas de libertad, de las cuales 27.656 son personas condenadas que se encuentran en contexto de encierro. ${ }^{1}$ Dentro de estos, un $91,6 \%$ son hombres y un $8,4 \%$ mujeres. Un tercio del total de esta población corresponde a imputados, ${ }^{2}$ es decir, personas en prisión preventiva a la espera de un juicio oral. ${ }^{3}$ Conforme al Instituto Nacional de Derechos Humanos, las tasas de hacinamiento en Chile en promedio, a nivel nacional, ascienden a un 100,4\% de ocupación, ${ }^{4}$ pero en algunos recintos alcanza más del $200 \% .{ }^{5}$ La tasa de prisionización es de 211 privados de libertad por cada 100.000 habitantes. ${ }^{6}$ Esta tasa, si bien es alta, se aleja de las tasas de países como El Salvador o Estados Unidos que lideran dicho ranking. ${ }^{7}$ No obstante, considerando que una parte importante de las condenas privativas de libertad se deben en un $62 \%$ a delitos contra la propiedad, se trata de una tasa que debe ser tomada con preocupación. ${ }^{8}$

\footnotetext{
${ }^{1}$ GENCHI (2019a), passim.

${ }^{2}$ Por motivos de economía de espacio, se hablará en términos masculinos, cuando en realidad el artículo incluye a población masculina, femenina y LGBTIQ privada de libertad.

${ }^{3}$ GENCHI (2019a), passim.

${ }^{4}$ INTERNATIONAL CENTRE FOR PRISON STUDIES (2019).

${ }^{5}$ INDH (2018) p.38-39

${ }^{6}$ INTERNATIONAL CENTRE FOR PRISON STUDIES (2019).

${ }^{7}$ INTERNATIONAL CENTRE FOR PRISON STUDIES (2019).

${ }^{8}$ GENCHI (2019b) Datos de diciembre-enero 2019, passim.
} 
La población penal, por su parte, presenta un perfil de mayor desventaja social ${ }^{9}$ Cuando se comparan los niveles socioeconómicos y educativos con los de la población general, se evidencia que se trata un grupo especialmente empobrecido, con pocas oportunidades educativas y laborales, y cuando estas se presentan, lo hacen en condiciones precarizadas. Asimismo, la prevalencia de consumo problemático y dependencia a las drogas y alcohol entre las personas privadas de libertad supera con creces los promedios nacionales. ${ }^{10} \mathrm{Se} \mathrm{trata}$, por tanto, de una población desaventajada incluso entre los más pobres de la sociedad chilena.

A lo anterior se suma que las personas privadas de libertad enfrentan obstáculos importantes para obtener información, asesoría legal, representación y participación en procesos judiciales. En Australia, un estudio ${ }^{11}$ describe algunos de estos problemas. La falta de información sobre procesos, servicios disponibles de defensa penitenciaria y la manera de acceder a ellos — por ejemplo, cómo lograr contactar al abogado defensor- dificulta el acceso a asesoría legal adecuada. Esto se debe a las múltiples desventajas que dificultan su acceso a información, tales como antecedentes de enfermedades mentales, drogadicción, así como dificultades cognitivas. Toda vez que estas dificultan a los internos entender, documentar y guardar registro sobre sus historiales personales, familiares y actividades criminales, arrestos o condenas previas. $^{12}$ Además, debido a sus escasos recursos económicos, los pagos que deben hacerse por acceder a documentos, fotocopias o llamados telefónicos desincentivan la formulación de peticiones. La circulación de información equívoca por parte de familiares y otros internos también conduce a malentendidos respecto de los cursos legales correspondientes. ${ }^{13}$

Tanto en Chile como en otros países, la dificultad de acceder a un teléfono o la imposibilidad por parte de las y los abogados para llamar a los internos o devolver llamadas, también restringe las posibilidades de comunicación. Asimismo, los prolongados tiempos de espera para acceder a información y servicios legales y las dificultades para obtener documentos y registros administrativos priva a los internos de los insumos necesarios para tomar decisiones informadas o contribuir con evidencia para sus causas. A veces, el acceso a documentación depende de la buena voluntad, disposición y capacidad del funcionario a cargo y no necesariamente de su posición institucional. El estudio del caso australiano ${ }^{14}$ señala que la brevedad de las entrevistas y la falta de privacidad para efectuarlas también merma las posibilidades de establecer un dialogo productivo entre la persona defendida y su abogado defensor.

La capacidad disminuida de los internos para procesar información en tiempos restringidos - como en entrevistas breves - o descifrar documentos escritos - cuando tienen bajo nivel de comprensión lectora o alfabetización - dificulta la posibilidad de entablar una relación de cooperación con el o la defensora. ${ }^{15}$ La falta de educación puede significar que presenten sus

\footnotetext{
${ }^{9}$ FUNDACIÓN PAZ CIUDADANA (FPC) (2016), passim; CARVACHO (2014), passim.

${ }^{10}$ GRUNSEIT et al. (2008), passim.

${ }^{11}$ GRUNSEIT et al. (2008) passim.

12 GRUNSEIT et al. (2008) passim.

${ }^{13}$ FEIERMAN (2006) passim.

${ }^{14}$ GRUNSEIT et al. (2008) passim.

${ }^{15}$ GRUNSEIT et al. (2008) passim.
} 


\section{Polít. Crim. Vol. 16, № 31 (Junio 2021), Art. 10, pp. 254-283 [http://politcrim.com/wp-content/uploads/2021/07/Vol16N31A10.pdf]}

solicitudes o expongan sus historias de manera vaga o equívoca, por lo que a primera vista sus casos pueden parecer insignificantes o no suscitar consideración o alarma por parte de los defensores o la administración penitenciaria. También, que los internos no comprendan plazos o requisitos dificulta la presentación de sus casos de manera eficaz y oportuna. ${ }^{16}$

En otro estudio sobre alfabetización de la población penal y acceso a la justicia en Estados Unidos, se evidencia que la falta de educación imposibilita a las personas privadas de libertad a elevar solicitudes tanto a la administración penitenciaria como a las cortes de justicia. ${ }^{17}$ También, debido a que la ley en Estados Unidos prohíbe la presentación reiterada de solicitudes por el mismo tema, usuarios que han presentado solicitudes confusas o incompletas tienen escasas oportunidades de rectificación. Según Feierman ${ }^{18}$ no tener acceso a algún tipo de asistencia legal puede equivaler a denegar en la práctica el derecho a petición. ${ }^{19}$ Por lo demás, en dichos contextos anglosajones, tanto internos y personal de custodia reportan también que la información que los abogados entregan es inconsistente y confusa. ${ }^{20}$

A su vez, la situación procesal y tiempo de confinamiento de quien está encarcelado también influye en su capacidad de comprender o solicitar asistencia legal ${ }^{21}$ En los primeros meses de encierro, los internos experimentan inestabilidad y estrés producto del proceso de adaptación a la realidad carcelaria. Dado que la mayoría que entra por primera vez a la cárcel no posee redes en prisión o el conocimiento necesario para proteger su integridad física o posesiones personales, resultan ser una población especialmente vulnerable a agresiones y robos. Asimismo, se ha evidenciado que en los primeros meses de encierro pueden presentar mayor prevalencia de intoxicación por drogas o problemas de salud mental. ${ }^{22}$

La dificultad de entrevistar a una persona cuando su capacidad mental o emocional está fuertemente comprometida, junto a la imposibilidad para procesar y comprender información legal durante el proceso de adaptación a las condiciones de encierro, sugieren que se debiera considerar el nivel de educación, etapa y tiempo de confinamiento para evaluar la capacidad de los internos de solicitar, acceder y obtener beneficios de la asistencia legal. ${ }^{23}$ Por último, una vez que se ha resuelto un caso, los privados de libertad a veces no comprenden los resultados u obligaciones que envuelve cierta decisión administrativa o judicial, debido a dificultades de compresión o por no haber tenido acceso a una entrevista de calidad o por tiempo suficiente con un representante legal. ${ }^{24}$

\footnotetext{
${ }^{16}$ FEIERMAN (2006), passim.

${ }^{17}$ FEIERMAN (2006), passim.

${ }^{18}$ FEIERMAN (2006), passim.

${ }^{19}$ La escolaridad promedio de la población penal chilena es baja. La muestra del reciente reporte de Fundación Paz Ciudadana indica que el 7,3\% de los entrevistados reportó ser analfabeto y más de un $80 \%$ declaró no tener educación escolar completa lo que permite suponer que la población penal en Chile está sujeta a similares desventajas que las reportadas en estudios comparados.

${ }^{20}$ GRUNSEIT et al. (2008), passim.

${ }^{21}$ GRUNSEIT et al. (2008), passim.

${ }^{22}$ FEIERMAN (2006), passim.

${ }^{23}$ GRUNSEIT et al. (2008), passim.

${ }^{24}$ GRUNSEIT et al. (2008), passim; CAMPBELL et al. (2015), passim.
} 
La población reclusa en Chile no está ajena a la situación recién planteada. Muchas de sus necesidades jurídicas dicen relación con gestiones propias del encierro (traslados de recintos, disminución de penas, beneficios intrapenitenciarios); mientras que otras dicen relación con sus vidas personales y relaciones familiares (pensiones alimenticias o divorcios). Además, esta población debe satisfacer sus necesidades jurídicas en un contexto normativo específico y tienen que ajustarse a una regulación administrativa dictada por la institución que custodia la cárcel (Gendarmería de Chile), con altos niveles de discrecionalidad y sin controles judiciales efectivos. Y si bien, conforme a la normativa internacional, la restricción de los derechos de las personas encarceladas debe limitarse a la privación de su libertad, en la práctica se les vulnera muchos otros derechos. De esta manera, la cárcel se despliega en un contexto donde confluye una población especialmente precarizada, con necesidades jurídicas complejas y muchas de ellas urgentes, bajo un régimen penitenciario arbitrario, sin mecanismos de control y desregulado legalmente.

El presente artículo busca entregar una radiografía de la defensa penitenciaria en Chile tomando en cuenta las especiales dificultades para su desarrollo y las condiciones legales existentes en cuanto a la ejecución penal.

\section{Antecedentes de la defensa penitenciaria en Chile}

La defensa penitenciaria es el asesoramiento jurídico para promover acciones judiciales o administrativas a fin de asegurar la correcta aplicación de las garantías constitucionales y acceso a la justicia de la población penal condenada a una pena privativa de libertad (Resolución Exenta №219 de 2017 que establece el Manual de Actuaciones Mínimas para la Defensa Penitenciaria). Este servicio es proveído por la Defensoría Penal Pública, institución estatal que externaliza los servicios de defensa penitenciaria.

La prestación del servicio de defensa técnica de la defensoría penitenciaria comprende el conjunto de acciones judiciales y extrajudiciales que la o el defensor penitenciario debe realizar durante el cumplimiento de la pena privativa de libertad y hasta su completa ejecución (Resolución Exenta No219 de 2017 que establece el Manual de Actuaciones Mínimas para la Defensa Penitenciaria). Sus inicios se remontan al año 2009, a través del trabajo entre la Defensoría Penal Pública y la Agencia Española de cooperación internacional para el desarrollo (AECID) que dio origen al piloto de la defensa penitenciaria. Luego, se transformó dicho piloto en un programa permanente de defensa especializada. El programa contempla distintas labores, tales como de difusión (del programa de defensa y estatuto jurídico de la persona condenada), de representación ante autoridades administrativas (ante Gendarmería de Chile, Comisiones especiales, el Ministerio de Justicia y todos sus servicios); y representación ante autoridades judiciales (Juez de Garantía, Tribunal Oral en lo penal, Cortes de Apelaciones y Corte Suprema). La representación judicial puede estar destinada a entablar acciones judiciales en caso de vulneración de derechos y garantías constitucionales o emprender procedimientos contemplados en la normativa penitenciaria generalmente destinados a acceder a beneficios penitenciarios (unificación de penas, sustitución, recursos de revisión y acciones constitucionales, entre otros). 


\section{Polít. Crim. Vol. 16, № 31 (Junio 2021), Art. 10, pp. 254-283 [http://politcrim.com/wp-content/uploads/2021/07/Vol16N31A10.pdf]}

Con todo, la misión declarada de la Defensoría Penal Pública es la defensa penal a las personas imputadas por delitos que carecen de representación jurídica, asegurando el derecho a defensa por un letrado y el debido proceso en el juicio penal. Como es posible ver, su misión se centra en la defensa penal en juicios y si bien la normativa constitucional extiende esta defensa hasta el término de la pena impuesta ${ }^{25}$ se trata de un servicio que no ha sido diseñado inicialmente para esta función. Por lo mismo, el desarrollo de la defensa penitenciaria en Chile se encuentra en proceso y, como se argumentará, se encuentra escasamente internalizada en las instituciones vinculadas a la cárcel en Chile.

En la actualidad, el equipo penitenciario debe ser conformado por un equipo interdisciplinario de, a lo menos, un abogado, un trabajador social y un asistente administrativo, repartidos en las distintas regiones del país. Si bien estos equipos se encuentran presentes a lo largo de Chile, un estudio estimó que para el año 2015 existía un defensor aproximadamente por cada mil internos. ${ }^{26} \mathrm{Su}$ trabajo, además, se realiza en ausencia de un "código" por lo que no existen procedimientos preestablecidos. Finalmente, el defensor penitenciario se enfrenta a una defensa que no tiene objetivos tan concretos como la defensa procesal. En estos casos, la libertad, la declaración de inocencia o la búsqueda de una condena menor son propósitos básicos de la defensa en el proceso judicial. En el caso penitenciario, la falta de empoderamiento y conocimiento legal redunda en un estado de mayor incertidumbre y desconocimiento respecto de las posibilidades legales de las personas condenadas.

Finalmente, existen tensiones en la comprensión que otras agencias dentro del sistema de justicia tienen respecto del alcance de la labor de los defensores penitenciarios. Gendarmería de Chile inicialmente se opuso a la presencia de defensores penitenciarios, ${ }^{27}$ lo que da cuenta de las barreras que imponen las culturas organizacionales de instituciones de las que se supone un deber de cooperación. Se ha demostrado cómo la intermediación de Gendarmería dificulta a los usuarios el acceso libre y sin discriminación a charlas sobre derechos y entrevistas con abogados. ${ }^{28}$ En cuanto a la relación con el poder judicial, la evidencia en Chile revela que jueces consideran a la labor penitenciaria como ajena a su esfera de competencia, e, incluso carecen de conocimiento sobre las materias que se les presentan. La diversidad de respuestas y culturas institucionales y su variación de acuerdo al recinto

\footnotetext{
${ }^{25} \mathrm{La}$ Constitución asegura a todas las personas la igual protección de la ley en el ejercicio de sus derechos y establece el derecho irrenunciable a toda persona imputada por un delito a ser asistida por un abogado defensor proporcionado por el Estado (artículo $19 \mathrm{~N}^{\circ}$ 3). El Código Procesal Penal establece que el imputado tendrá derecho a ser defendido por un letrado. En caso de carecer de abogado, el imputado tiene el derecho irrenunciable a la representación de un abogado provisto por el Estado (artículo 8), garantía que puede hacerse valer desde la primera actuación del procedimiento dirigido en su contra, hasta la completa ejecución de la sentencia (artículo 7; en la misma línea, artículos 93, 102 y 466 y siguientes del CPP). La Ley Orgánica de la Defensoría Penal Pública establece como misión del organismo proporcionar defensa penal a la población imputada que carezca de abogado (artículos 2 y 35 Ley 19.718, de manera similar, los artículos 10 y 22 de la Ley 19.880) El imputado tiene derecho a designar un abogado o acceder a un abogado provisto por el Estado y a comunicarse libre y privadamente con él (artículos 93 a 95 del Código Procesal Penal).

${ }^{26}$ UDP (2015), passim.

${ }^{27}$ INDH (2015), p. 174

${ }^{28}$ LIBEDINSKY (2015), p. 240
} 
penitenciario y ubicación geográfica dificulta la estandarización del programa chileno de defensa penitenciaria. ${ }^{29}$

La coordinación institucional resulta fundamental para el éxito de la labor de defensa penitenciaria. No obstante, el programa de defensa penitenciaria en Chile no contempló la implementación sistemática de instancias de coordinación institucional con agencias relacionadas, tales como Gendarmería de Chile, el Poder Judicial y el Ministerio Público. De este modo, personal administrativo de Gendarmería y tribunales han experimentado un aumento en su carga de trabajo por crecientes solicitudes de información, requerimientos y audiencias sin haber iniciado la adaptación institucional, presupuestaria, e incluso de infraestructura correspondiente. ${ }^{30}$ Por otro lado, los defensores penitenciarios deben también coordinar su labor con el Ministerio Público y el Instituto Nacional de Derechos Humanos. Dado que deben ejercer las acciones judiciales por vulneración de derechos de la población penal -en casos de torturas, lesiones, abuso sexual o violación, por ejemplo- los defensores requieren necesariamente la intervención del Ministerio Público para iniciar una investigación oficial y efectiva que concluya con la identificación y sanción de los agentes responsables. ${ }^{31}$ Por esta razón, el citado estudio recomienda capacitar al personal penitenciario -Gendarmería, en el caso chileno- para lograr su cooperación en la provisión de asistencia jurídica.

La defensa penitenciaria, por tanto, se despliega en un contexto particular, el cual, si bien se encuentra regido por una institución particular, Gendarmería, es un espacio en el que confluyen diversas instituciones con atribuciones a veces específicas y en otras ocasiones, compartidas respecto de la población penitenciaria.

\section{Marco teórico. Cultura de la defensa penitenciaria}

El equipo de defensa penitenciaria debe servir a una población vulnerable, generalmente proveniente de bajos estratos socioeconómicos, y que demuestra mayor prevalencia de adicciones y enfermedades mentales que el público en general ${ }^{32}$ Como ya se ha señalado, a diferencia de otros actores del sistema de justicia como jueces o fiscales, quien ejerce el rol de defensa debe establecer una relación de cooperación prolongada en el tiempo con el usuario del sistema penal ${ }^{33}$, y que implica la toma de decisiones de manera consecutiva. ${ }^{34}$ Asimismo, a diferencia de la defensa penal general, la defensa penitenciaria exige al defensor un mayor nivel de intervención y entrevistas en terreno, actuaciones administrativas, participación en equipos interdisciplinarios y emprender incluso gestiones durante el periodo post penitenciario. ${ }^{35}$

El defensor penitenciario usualmente enfrenta barreras institucionales provenientes de agencias gubernamentales dentro del sistema de justicia. Existen conflictos, por ejemplo,

\footnotetext{
${ }^{29}$ LIBEDINSKY (2015), passim.

${ }^{30}$ LIBEDINSKY (2015), passim.

${ }^{31}$ INDH (2015), p. 180

${ }^{32}$ GRUNSEIT et al. (2008), passim.

${ }^{33}$ CAMPBELL et al. (2015), passim.

${ }^{34}$ CLAIR (2018), passim.

${ }^{35}$ LIBEDINSKY (2015), passim.
} 


\section{Polít. Crim. Vol. 16, № 31 (Junio 2021), Art. 10, pp. 254-283 [http://politcrim.com/wp-content/uploads/2021/07/Vol16N31A10.pdf]}

entre el defensor y el personal de custodia, lo que dificulta la prestación adecuada de servicios. En estos casos, la administración penitenciaria puede establecer horarios de acceso en días y horas que no coinciden con la disponibilidad de los abogados, establecer restricciones en el acceso a llamadas telefónicas por parte de los internos o impedir que internos asistan al día de la entrevista programada con su abogado. ${ }^{36}$ Los defensores penitenciarios enfrentan dificultades para lidiar con las facultades discrecionales de la administración penitenciaria, como acceder físicamente a los recintos penitenciarios en horarios convenientes y obtener información oportuna y pertinente sobre las condiciones materiales y situación procesal de los usuarios. ${ }^{37}$ Por lo demás, la autoridad administrativa interviene en la relación entre la población penal y el defensor penitenciario y puede seleccionar discrecionalmente a los internos con acceso a asesoría jurídica.

La resistencia proveniente de las lógicas institucionales de otros servicios públicos y su falta de cooperación puede arriesgar el aislamiento institucional de los defensores penitenciarios y determinar el fracaso de su labor. Grunseit et al., ${ }^{38}$ por ejemplo, indican que la falta de coordinación puede contribuir a la confusión que los internos experimentan cuando navegan el sistema de justicia. Su estudio evidencia los problemas que surgen debido a la falta de coordinación entre instituciones, la fragmentación de información, la presencia de distintos expertos que abordan el mismo problema (personal administrativo y abogados, por ejemplo), la activación simultánea de distintos canales de acción para resolver el mismo problema y la presencia de varios profesionales con distintos niveles de conocimiento sobre la situación del interno y posibles respuestas institucionales. Esto puede significar duplicar esfuerzos, desperdiciar recursos, generar confusión e incluso impedir la solución del problema en concreto.

El contexto laboral de los defensores penitenciarios es también adverso. Estudios describen la excesiva carga laboral de los defensores penitenciarios y el escaso acceso a recursos para ejercer su labor. ${ }^{39}$ Los usuarios pueden percibir esta circunstancia. En distintos estudios, los usuarios reportan creer que los defensores que les asigna el Estado, aunque competentes, tienen sobrecarga laboral y, por lo tanto, no tienen tiempo ni incentivos suficientes para defender sus causas. ${ }^{40}$ Por esta razón, los usuarios permanentemente comparan el servicio público gratuito de defensa con la expectativa de haber podido recibir asesoría privada, ya que presumen que los incentivos monetarios determinan el nivel de compromiso por la causa. ${ }^{41}$ Los defensores entonces experimentan frustración o incluso antipatía en contra de usuarios difíciles que muestran escepticismo o que cuestionan permanentemente su autoridad y conocimiento. ${ }^{42}$

Finalmente, cabe destacar los riesgos que envuelve la actividad del defensor para su salud mental. En un estudio sobre burnout y síndrome de fatiga de la compasión ${ }^{43}$ se descubre que

\footnotetext{
${ }^{36}$ GRUNSEIT et al. (2008), passim.

${ }^{37}$ LIBEDINSKY (2015), passim; GRUNSEIT et al. (2008), passim.

${ }^{38}$ GRUNSEIT et al. (2008), passim.

${ }^{39}$ LEMOS (2000), passim.

${ }^{40}$ CLAIR (2018), passim.

${ }^{41}$ CAMPBELL et al. (2015), passim.

${ }^{42}$ CLAIR (2018), passim.

${ }^{43}$ NORTON et al. (2015), passim.
} 
abogados, especialmente aquellos que cumplen labores de defensa, se encuentran altamente expuestos a estos trastornos. La excesiva carga laboral, el desarrollo de su labor en solitario, la exposición constante al sufrimiento de los clientes y la necesidad de subordinar sus propias emociones a las exigencias de su trabajo puede resultar en que los abogados experimenten ansiedad crónica, irritabilidad, inhabilidad de mantener relaciones personales estables, irrupción de pensamientos intrusivos, minimización o insensibilidad ante las necesidades de sus clientes, y debilitamiento del sentido y motivación personales. ${ }^{44}$

\section{Métodos}

Se llevó a cabo un levantamiento de datos cualitativo y cuantitativo en 15 centros penitenciarios de 7 regiones de Chile, ${ }^{45}$ a fin de proveer una radiografía de la defensa penitenciaria en Chile. Para ello, se buscó determinar el nivel de cumplimiento de los equipos de defensa penitenciaria del país - compuestos por abogados defensores, trabajadores sociales y administrativos-, de los estándares de defensa penitenciaria consignados en su Manual de Actuaciones Mínimas (en adelante "MAMP”).

En cuanto a las fuentes de información, se aplicaron 766 pautas de observaciones no participantes de las primeras entrevistas que realizan los profesionales de defensa penitenciaria en los penales con los y las internas que lo solicitan; y 616 pautas de chequeo de carpetas de casos y su contraste con la información subida al Sistema Informático de Gestión de Defensa Penal (en adelante "SIGDP"). Por su lado, se realizó un terreno cualitativo de 19 entrevistas a defensores penitenciarios ( 8 defensores y 11 funcionarios del área operativa de Gendarmería de Chile), y 9 grupos focales con personas privadas de libertad en 8 centros penitenciarios auditados. ${ }^{46}$ Dichos datos fueron triangulados con el análisis de fuentes secundarias, tales como la base de datos de requerimiento de la defensa penitenciaria del año 2018 que contaba con información de 24.189 primeras entrevistas y 7.088 requerimientos terminados en dicho año, junto a documentación interna de la institución. Los resultados pasaron por un proceso de validación, a través de un panel de expertos/as, ${ }^{47}$ una presentación final a directores regionales de la defensa penitenciaria a nivel nacional, y un cuestionario web a los equipos de defensa penitenciaria (defensores y trabajadores sociales) de todas las regiones del país, obteniendo 92 respuestas en total y una tasa de respuesta del $80 \%$.

\footnotetext{
${ }^{44}$ NORTON et al. (2015), passim.

${ }^{45}$ Arica, Antofagasta, Coquimbo, Valparaíso, RM (Sur y Norte); Valparaíso; Biobío.

${ }^{46}$ CP Arica; CCP Antofagasta; CCP La Serena; CP Valparaíso; CDP Santiago Sur; CP Puente Alto; CPF Santiago, CCP Biobío.

${ }^{47}$ El panel de expertos se llevó a cabo el día 15 de marzo del 2019 en las dependencias de la Defensoría Penal Pública, con el objetivo de identificar, luego de una deliberación colectiva, cuáles eran las características centrales que deberían cumplir el sistema y la defensa jurídica durante la ejecución de la pena privativa de libertad. A esta sesión asistieron 6 expertos de la materia, constituidos como especialistas de diferentes profesiones e instituciones del país: dos funcionarios/as de Gendarmería de Chile, una representante del Ministerio de Justicia y Derechos Humanos, una representante del mundo académico (de la Universidad de Chile), y dos representantes de organizaciones o centros académicos vinculados a la temática penitenciaria (Paz Ciudadana y Mujer Levántate).
} 


\section{Polít. Crim. Vol. 16, No 31 (Junio 2021), Art. 10, pp. 254-283 [http://politcrim.com/wp-content/uploads/2021/07/Vol16N31A10.pdf]}

El análisis cuantitativo fue de tipo descriptivo univariado y bivariado. Por su parte, el análisis cualitativo estuvo basado en la técnica de análisis de Grounded Theory. ${ }^{48}$ Posteriormente se utilizaron distintos enfoques de métodos mixtos, ${ }^{49}$ tanto de tipo exploratorio, integrado, triangulado y explicativo con el objetivo de que los datos cualitativos ayuden a explicar o fortalecer los datos cuantitativos obtenidos en un inicio.

\section{Resultados}

\subsection{Radiografía actual de la defensa penitenciaria en Chile}

La defensa penitenciaria se desenvuelve en un contexto de poco conocimiento por parte del personal penitenciario sobre los Derechos Humanos de los privados de libertad. Al mismo tiempo, tampoco los privados de libertad tienen conciencia de sus derechos. En efecto, existe escasa difusión de la Defensa Penal Penitenciaria hacia internos. Esto, al igual que en la experiencia comparada, es usualmente aprovechado por abogados privados inescrupulosos que abusan de su posición asimétrica frente los internos. ${ }^{50}$

Junto con ese contexto de poca capacidad jurídica y empoderamiento legal, la defensa penitenciaria se encuentra fragmentada en varias instituciones públicas. Al rol de Gendarmería de Chile (GENCHI) y de la Defensoría Penal Pública, debe sumarse las funciones del Instituto Nacional de Derechos Humanos (INDH), la Fiscalía Nacional y el Poder Judicial, todos los cuales de diversas formas supervisan el funcionamiento de las cárceles en Chile. En este contexto de fragmentación institucional, las funciones se entrecruzan, se duplican y algunas de ellas, no son desempeñadas. Junto con el aislamiento institucional de los defensores penitenciarios, la consecuencia más seria es la confusión por parte de usuarios al momento de usar el sistema de justicia.

En términos concretos, la práctica de la defensa penitenciaria se rige de acuerdo a lo estipulado en su MAMP. Dicho Manual da cuenta de los procesos de atención a las personas condenadas privadas de libertad. Este proceso comienza con una solicitud de requerimiento de defensa penitenciaria, la cual puede ser presentado por una persona condenada privada de libertad (persona usuaria) o por otros actores vinculados a la defensa penitenciaria, que pueden ser un familiar, de GENCHI, y el INDH, u otras instituciones.

Una vez recibida esta solicitud, el defensor debe asistir al penal a una primera entrevista a visitar y saber cuál es el requerimiento de defensa, y debe ser realizada en un plazo máximo de 20 días. En dicha entrevista, el/la profesional de la defensa penitenciaria debe completar una "ficha de primera entrevista" y consultar con el usuario qué requerimiento(s) tiene que el defensor deba atender. A partir de las primeras entrevistas, surgen uno o más requerimientos, los cuales el equipo defensor penitenciario tiene un plazo establecido para terminarlo, a través de diversas gestiones. En este proceso, un usuario puede solicitar más de una primera entrevista, y en una primera entrevista de un usuario pueden haber surgido uno o más requerimientos, los que a su vez se traducen en varias gestiones. Todo lo recién

\footnotetext{
${ }^{48}$ CHARMAZ (2006), passim.

${ }^{49}$ CRESWELL y PIANO CLARK (2007), passim.

${ }^{50}$ CAMPBELL et al. (2015), passim.
} 
descrito suele ser traspasado a carpetas físicas y digitales. Estas últimas subidas a un sistema informático llamado SIGDP, el cual va registrando las acciones y avances del trabajo de defensa penitenciaria a lo largo del país.

Tabla 1: Fotografía de acciones y principales actores de la Defensa Penitenciaria en Chile 2018

\begin{tabular}{|c|c|c|c|c|c|}
\hline Región & $\begin{array}{c}\text { Primeras } \\
\text { entrevistas } \\
\text { realizadas } \\
2018\end{array}$ & $\begin{array}{c}\text { Requerimientos } \\
\text { terminados } \\
2018\end{array}$ & $\begin{array}{l}\text { Gestiones } \\
\text { realizadas } \\
\text { por } \\
\text { región } \\
2018\end{array}$ & $\begin{array}{l}\text { Usuarios con } \\
\text { requerimientos } \\
\text { terminados } \\
2018\end{array}$ & $\begin{array}{c}\text { Cantidad de } \\
\text { defensores } \\
\text { penitenciarios } \\
2018^{*}\end{array}$ \\
\hline Arica y Parinacota & 712 & 119 & 539 & 112 & 4 \\
\hline Tarapacá & 844 & 213 & 680 & 197 & 3 \\
\hline Antofagasta & 2061 & 887 & 1605 & 708 & 6 \\
\hline Atacama & 322 & 72 & 299 & 67 & 1 \\
\hline Coquimbo & 1173 & 403 & 876 & 319 & 3 \\
\hline Valparaíso & 2346 & 473 & 2045 & 416 & 6 \\
\hline $\begin{array}{l}\text { Metropolitana } \\
\text { Norte }\end{array}$ & 5472 & 1633 & 4875 & 1238 & 11 \\
\hline Metropolitana Sur & 2101 & 813 & 1923 & 584 & 6 \\
\hline $\begin{array}{l}\text { Libertador } \\
\text { Bernardo } \mathrm{O}^{\prime} \\
\text { Higgins }\end{array}$ & 1267 & 597 & 1076 & 393 & 7 \\
\hline Maule & 1821 & 384 & 1568 & 330 & 9 \\
\hline Biobío & 2003 & 390 & 1864 & 347 & 8 \\
\hline La Araucanía & 1163 & 237 & 1122 & 210 & 2 \\
\hline Los Ríos & 564 & 184 & 510 & 162 & 1 \\
\hline Los Lagos & 1240 & 362 & 1184 & 303 & 6 \\
\hline Aysén & 705 & 158 & 372 & 103 & 2 \\
\hline $\begin{array}{l}\text { Magallanes y } \\
\text { Antártica Chilena }\end{array}$ & 395 & 163 & 342 & 119 & 1 \\
\hline Total nacional & 24189 & 7088 & 20880 & 5608 & 68 \\
\hline
\end{tabular}

Fuente: Propia elaboración de acuerdo con base de datos de primeras entrevistas, gestiones y requerimientos DPP 2018.

*Esta cantidad corresponde al total de defensores penitenciarios que pasaron por este trabajo en las regiones durante el 2018. En la práctica, en general son alrededor de 60 profesionales trabajando al mismo tiempo a nivel país.

Como se observa en la tabla anterior, durante el año 2018 se registraron 24.189 primeras entrevistas realizadas a personas condenadas privadas de libertad que solicitaron una visita por algún requerimiento por parte de un defensor o trabajador social de defensa penitenciaria, las cuales terminaron en 7.088 requerimientos terminados. Esto se tradujo en 20.888 gestiones realizadas. En total anual, hubo 5.608 usuarios atendidos por un requerimiento tramitado y terminado por la Defensoría Penal Penitenciaria a lo largo de Chile, ${ }^{51}$ todos atendidos por 68 defensores penitenciarios responsables y sus equipos para ese año.

${ }^{51}$ Un requerimiento es la necesidad jurídica planteada por el interno del recinto penal. 


\section{Polít. Crim. Vol. 16, No 31 (Junio 2021), Art. 10, pp. 254-283 [http://politcrim.com/wp-content/uploads/2021/07/Vol16N31A10.pdf]}

De estas cifras se desprende que, durante el 2018, solo un $20 \%$ de personas privadas de libertad con derecho a defensa penitenciaria efectivamente la utilizó. Asimismo, los datos muestran que hubo un defensor penitenciario por cada 394 usuarios potenciales de la defensa penitenciaria y uno por cada 82 usuarios del sistema de defensa penitenciaria. A su vez, esto da cuenta que la defensa penitenciaria tiene una cobertura del $20 \%$ del total de población objetivo de su servicio. Esto se sintetiza en la siguiente tabla:

Tabla 2: Cobertura de la Defensa Penitenciaria en Chile 2018

\begin{tabular}{|c|c|c|l|l|l|}
\hline $\begin{array}{l}\mathrm{N}^{\circ} \text { de } \\
\text { usuarios } \\
\text { potenciales* }\end{array}$ & $\begin{array}{l}\mathrm{N}^{\circ} \text { de usuarios } \\
\text { efectivos** }\end{array}$ & $\begin{array}{l}\% \text { de } \\
\text { usuarios } \\
\text { efectivos }\end{array}$ & $\begin{array}{l}\mathrm{N}^{\circ} \text { de } \\
\text { defensores } \\
\text { penitenciarios } \\
2018\end{array}$ & $\begin{array}{l}\text { Razón de usuarios } \\
\text { potenciales* por } \\
\text { defensor } \\
\text { penitenciario }\end{array}$ & $\begin{array}{l}\text { Razón de } \\
\text { usuarios } \\
\text { efectivos** por } \\
\text { defensor } \\
\text { penitenciario }\end{array}$ \\
\hline 26.815 & 5.608 & $20 \%$ & 68 & 394 & 82 \\
\hline
\end{tabular}

Fuente: Propia elaboración en base a base de datos de primeras entrevistas, gestiones y requerimientos DPP 2018 y Compendio estadístico de GENCHI $2018^{52}$.

* Personas privadas de libertad con condena en 2018.

** Usuarios de defensa penitenciaria atendidos y con requerimientos terminados durante el 2018.

Respecto a la distribución por género y edad de los internos e internas usuarias que han sido atendidas por la DPP, se destaca que casi la totalidad de los usuarios corresponde al género masculino, alcanzando el 89,3\% del total, vale decir, aproximadamente sólo 1 de cada 10 usuarios fueron mujeres - lo que se condice con la proporción de personas encarceladas a nivel nacional - En cuanto al promedio de edad de los usuarios, a nivel nacional se sitúa en 34,1 años. Al desagregar la edad según el género, se encuentra que las mujeres promediaron 36,3 años, mientras los hombres llegaban a 33,9 años.

Del total de solicitud de primeras entrevistas, la mayoría de estos son solicitados por los mismos condenados $(63,6 \%)$ o por su familia $(11,7 \%)$, mientras que sólo un $17.7 \%$ surgen de la defensoría. Otras instituciones de justicia (GENCHI, tribunales, y otros), son actores secundarios en activar la defensa penitenciaria (7\% entre todos ellos). De esta forma, la defensoría penitenciaria, así como las otras instituciones vinculadas al sistema penal y justicia, juegan más bien un rol reactivo en la sustanciación de las necesidades jurídicas de las personas privadas de libertad. Lo anterior se ilustra en la siguiente gráfica.

${ }^{52}$ GENCHI (2018), passim. 
Gráfico 1: Actores que originan de demandas de defensa penitenciaria. N=7088

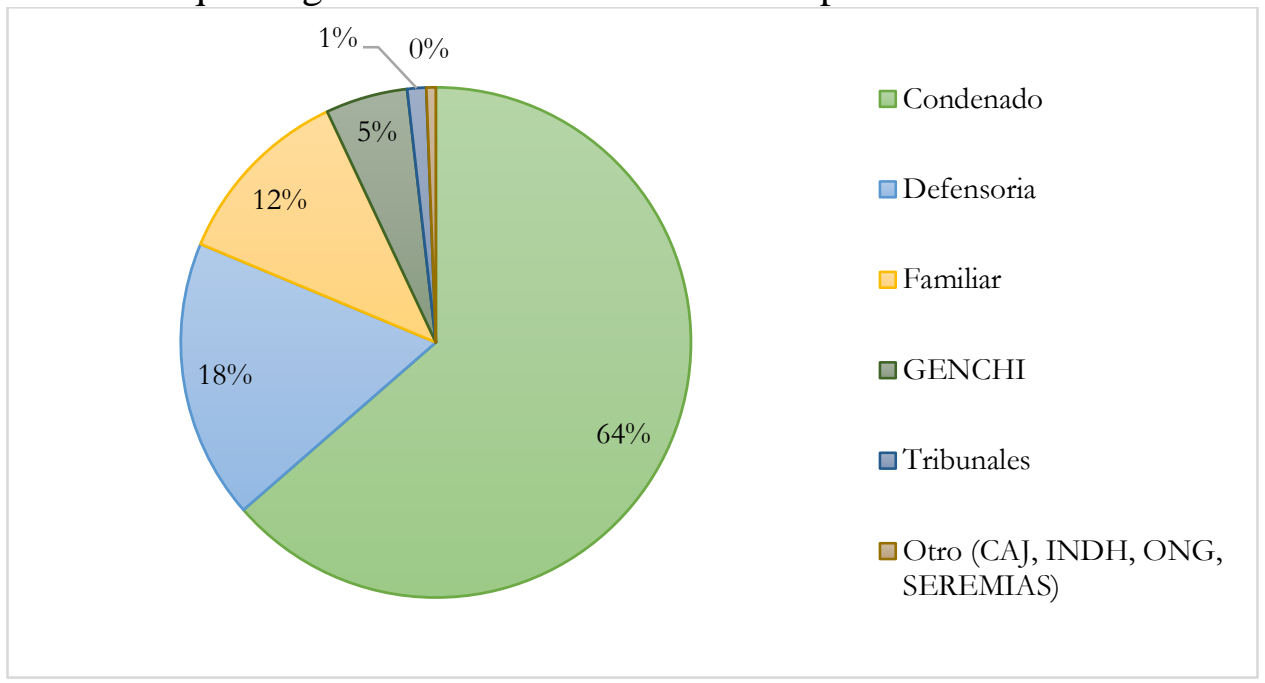

Fuente: propia elaboración en base a datos DPP (2018)

Sobre este último aspecto, es relevante destacar las diferencias según género de la persona privada de libertad. Mientras los defensores señalan que, en el caso de los hombres, son sus familiares quienes suelen presentar solicitudes, requerimientos, o acercarse a las oficinas, en el caso de las mujeres esto no es así. Como señala un defensor penitenciario:

“(...) la mujer no tiene una red de apoyo (...) yo acá [en la oficina en el centro de Santiago] no atiendo gente casi. Con suerte por teléfono habrá gente que me llama o vía electrónica, porque la familia está a cargo de otros niños" (Defensor penitenciario CPF Santiago).

Como fue señalado, esta frase contrasta con lo que expresan defensores penitenciarios de cárceles masculinas, quienes incluso confiesan que su trabajo fuera de los penales con los familiares llega a equiparar la demanda legal y de apoyo emocional que es solicitada por los mismos presos internados en las cárceles. Asimismo, esto es reforzado por palabras de los privados de libertad, quienes en muchos casos reconocen el rol de sus familiares y particularmente de las mujeres para poder tener un acceso a defensa y que se cumplan sus necesidades jurídicas:

"E: ¿Tú cómo accediste a este defensor penitenciario?

$\mathrm{H}$ : Por mi familia. Si yo no hubiese tenido a mi señora, yo todavía estuviese en Rancagua" (CDP Santiago Sur - Focus Group).

Lo anterior refleja cómo las mujeres en privación de libertad se ven en desventaja de acceso a justicia en comparación a sus pares hombres. Esto habla de la importancia de continuar haciendo charlas de difusión y entrega de afiches de la defensa penitenciaria en los penales femeninos, para que ellas mismas hagan valer sus derechos y solicitar ayuda.

Como ya se señaló, la defensa penitenciaria se compone de variadas gestiones. Esto significa que, durante el proceso de tramitación de un requerimiento, existen una serie de acciones destinadas a cumplir con ellos, las cuales son conocidas como gestiones, que pueden ser 


\section{Polít. Crim. Vol. 16, № 31 (Junio 2021), Art. 10, pp. 254-283 [http://politcrim.com/wp-content/uploads/2021/07/Vol16N31A10.pdf]}

realizadas tanto por defensores como por el resto del equipo de defensa. Como ejemplos de gestiones realizadas, se encuentran las visitas a las cárceles o domiciliarias, solicitudes de información a Gendarmería o Tribunales, audiencias, presentaciones de recursos, entre otras. Durante el año 2018 se registraron 20.880 gestiones para realizar los requerimientos en todas las regiones del país, las cuales en un $91 \%$ son realizadas por abogados, mientras que una porción menor, de $9 \%$, es llevada a cabo por los trabajadores sociales de los equipos.

Una de las gestiones centrales son las visitas para la entrevista con el interno. El MAMP define una visita como "efectiva" cuando el o la defensora logra realizar la visita planificada para entrevistar a la persona privada de libertad de manera exitosa, mientras que una visita no efectiva corresponde la frustración de esta. Esto puede ocurrir por diversas razones, ya sea porque el interno está en visita, taller u oficio o porque rechazó voluntariamente participar de la entrevista, entre otras. La observación participante dio cuenta que 1 de cada 5 visitas auditadas fallaron al no poder contar con la presencia de la persona privada de libertad en la primera entrevista. De las visitas no efectivas, en la mayoría de los casos no se pudo identificar la razón de la inasistencia $(72 \%)$. En el resto de los casos, la visita se frustró por estar el interno en otra actividad (9\%), rechazo voluntario (6\%) y un conjunto de otras razones (13\%): riñas internas previas a la visita, fallecimiento, enfermedad, o que el o la interna no se encontraba en el penal por estar en tribunal o en salida controlada al medio libre.

Para los defensores, la primera entrevista es crucial para mostrar la primera impresión a quien sería su usuario de defensa. En palabras de un defensor penitenciario, esta instancia representa una de las labores más importantes de su trabajo, pues al entrevistar a la persona privada de libertad, una situación:

“(...) indispensable (...) lo que lo hacemos nosotros es decirle al usuario qué es lo que tiene que saber porque muchas veces no tiene idea en qué servimos. Si bien es cierto que hacemos actos de charlas, pero no saben bien cuanto es la gama que podemos abarcar. Entonces eso es bueno ilustrarlo, creo que es lo primordial para entregar una buena línea recta de trabajo con la persona" (CPF Santiago - Entrevista Defensor).

Cabe señalar además que, en su mayoría, las entrevistas se desarrollan en espacios e infraestructura insuficiente en las cárceles. Lo anterior, no solo atenta contra la privacidad del interno para dar cuenta de sus peticiones al defensor penitenciario; sino que también atenta con el acceso a este servicio y al tiempo de atención dedicado a cada interno. En palabras de los internos y los defensores, la infraestructura se define como incómoda, poco privada, e incluso en muchas ocasiones no existen las condiciones para realizar las entrevistas sentadas, teniendo que desarrollarlas a pie y con tiempos escasos.

Por lo demás, la observación de entrevistas mostró que en general, los aspectos básicos personales y judiciales son generalmente preguntados. Por el contrario, sólo en un tercio de las primeras entrevistas $(35,5 \%)$ se profundizó sobre alguno de los antecedentes de vulnerabilidad de los usuarios de la defensa penitenciaria, esto es, tratarse de una madre con hijo lactante, migrante o extranjero, pertenecer a un pueblo originario o ser LBGTIQ+. En efecto, la orientación sexual, prácticamente no se pregunta en casi ninguna entrevista (1\%). Luego, en menos de la mitad de los casos se pregunta a una mujer si es madre de un/a hijo/a 


\section{CARVACHO, Pablo; VALDÉS, Amalia; MATEO, Mariel: "El derecho a la defensa \\ penitenciaria en Chile: cuando no hay derecho".}

lactante $(42,3 \%)$ y en una proporción similar de usuarios atendidos (solo en el $42,8 \%$ de los y las condenadas) se les pregunta sobre si pertenecen a algún pueblo originario. Asimismo, sólo en aproximadamente la mitad de los casos (55\%) la defensa penitenciaria profundiza sobre las actividades y programas de reinserción del interno.

Dichas primeras entrevistas en el 2018, se tradujeron en 7.088 requerimientos terminados a lo largo del país. De acuerdo al MAMP, los requerimientos pueden ser divididos en judiciales y administrativos, dependiendo del tipo de tramitación que deba realizarse. ${ }^{53}$ A nivel nacional, el 73,2\% de los requerimientos fueron administrativos, y 26,8 de tipo judicial. Específicamente, el requerimiento más solicitado a nivel país fueron aquellos relacionados a las libertades condicionales representando casi un tercio (el 27,8\%) de las solicitudes totales, lo cual se tradujo en 1.972 solicitudes. En segundo lugar, se encuentran las solicitudes de traslado de unidad penal, las cuales alcanzaron 1.023 solicitudes $(14,4 \%)$, particularmente significativas en RM Norte (el $21,6 \%$ de los requerimientos de dicha región) y Coquimbo $(17,3 \%)$. Por último, las solicitudes de abono significaron el 11,8\% llegando a un total de 844 solicitudes.

A continuación, se presentan gráficos que reflejan los principales requerimientos solicitados a la defensa penitenciaria nivel país en el 2018, mostrando que la solicitud de libertad condicional es la principal demanda de los internos, seguida de traslado de unidad penal y de solicitud de abono de cautelares. Como se detalla en el gráfico a continuación, estas solicitudes pueden ser tramitadas por vías administrativas o judiciales, aunque como ya se señaló, las principales demandas y gestiones que realizan los defensores penitenciarios son de tipo administrativas.

\footnotetext{
${ }^{53}$ A pesar de que esta es una clasificación bastante utilizada en la práctica de la defensoría, no son categorías totalmente consistentes. Hay requerimientos que pueden ser considerados tanto administrativos como judiciales, dependiendo del momento y de las gestiones vinculadas. Por ejemplo, una solicitud de traslado puede ser iniciada como un requerimiento administrativo y luego terminar en una instancia judicial. Dado esto, la descripción realizada de los requerimientos según estas categorías puede ser poco explicativa de la práctica de defensa penitenciaria.
} 


\section{Polít. Crim. Vol. 16, No 31 (Junio 2021), Art. 10, pp. 254-283 [http://politcrim.com/wp-content/uploads/2021/07/Vol16N31A10.pdf]}

Gráfico 2: Principales requerimientos solicitados a defensa penitenciaria 2018. N=7088

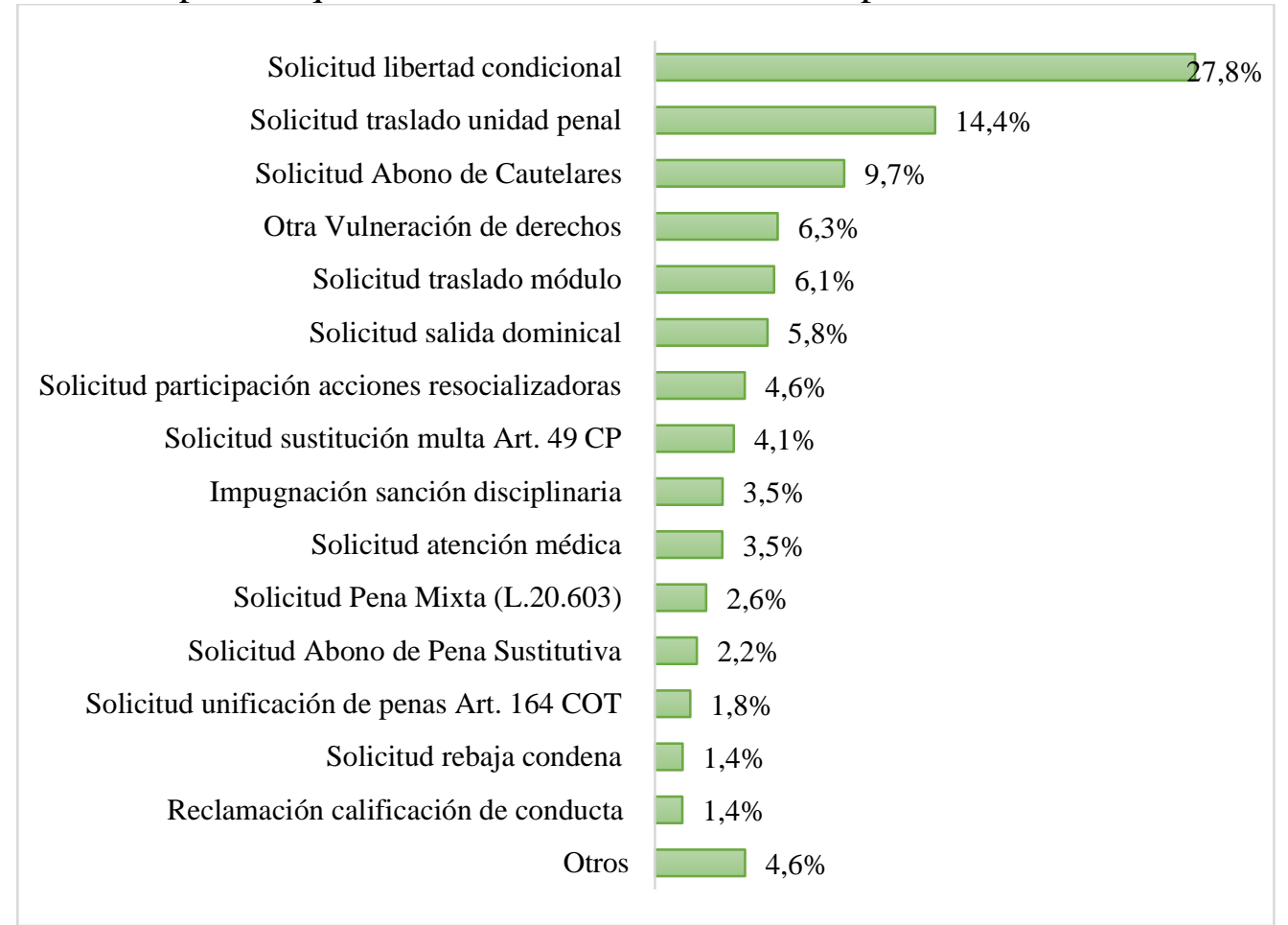

Fuente: propia elaboración en base a datos DPP (2018)

*Entre otros, adecuación de pena, visitas, salidas, prescripción de pena e indultos, solicitud traslado internacional; recurso de revisión; solicitud indulto; solicitud declaración enajenación mental Art. 482 CPP; solicitud pago parcialidades multa Art. 70 inc. 2 CP; solicitud restitución especies retenidas Art. 470 CPP; solicitud de devolución de caución; solicitud salida fin de semana; impugnación de traslado; solicitud salida esporádica; solicitud salida diaria; solicitud visita íntima.

Como ya se señaló, además, la defensa penitenciaria se conduce en base a una serie de instrumentos, fichas de entrevistas, carpetas físicas y carpetas digitales. En base a la revisión de estos instrumentos se pudo determinar el nivel de completitud de estos y la consistencia de la información en las carpetas con la que se encuentra en el sistema informático. En cuanto a la completitud de las carpetas estas lograron una tasa cercana, tanto para la carpeta física como para la digital, de 54,9\% y 58,7\%, respectivamente. Esto significa que los sistemas de recopilación de información son altamente deficientes y que se trabaja con escasa información de los casos particulares. En cuanto a la consistencia de la información contenida en ambas carpetas, se elaboró un índice que mostró que niveles de consistencia bajo de $36,2 \%$. Esto es preocupante sobre todo considerando que los datos y documentos que aquí son exigidos guardan directa relación con la entrega de un servicio óptimo, transparente, eficiente.

Por otro lado, de las entrevistas y focus groups con los internos, se observó un amplio desconocimiento del derecho a la defensa. En este sentido, los internos señalan una comprensión estrecha de los problemas justiciables, principalmente lo referido a requerimientos judiciales. Así, los números no reflejan necesariamente las necesidades de esta población sino lo que se cree que se puede pedir. En cuanto a sus percepciones sobre el servicio de defensa penitenciaria, en muchos casos los usuarios rescataban el trabajo y 
vocación de ciertos defensores, pero la mayoría expresó descontento en cuanto a su poca efectividad, interés, y tiempo dedicado para escucharlos o preguntar.

"No hay tiempo. ¿Usted cree que se va a poner a conversar con uno media hora, $<<y \ldots$ cuéntame tus problemas $>>\ldots$ si el hombre está pensando en la mente y rapidito, $<<$ hazle rápido porque tengo que atender al que sigue, hay una fila ahí >> (...) y tú estás con un abogado ahí y miras atrás tuyo y ves que hay 8 o 9 más" (CPD Santiago Sur, Focus Group).

La poca duración de entrevistas fue observada en terreno. En efecto, las entrevistas dadas a los internos duraban en promedio 9,44 minutos, siendo en el CPD Santiago Sur donde se observaron las entrevistas más cortas: 7,01 minutos de promedio, incluyendo algunas de 1 minuto, tiempo insuficiente para realizar una entrevista que pregunte los aspectos sociojurídicos de la vida de una persona.

Finalmente, el proceso de defensoría penitenciaria, — vale decir, desde que se eleva la solicitud de atención, se realizan las gestiones para el requerimiento solicitado, hasta que se realiza la entrevista de cierre-, dura en promedio 68,7 días. ${ }^{54}$ Esto significa que, en general, cada proceso dura alrededor de dos meses sin perjuicio de que la variación entre regiones, en este aspecto es considerable. Así, en Arica los procesos pueden llegar a durar incluso hasta 3 meses en promedio (existiendo una diferencia de 25 días entre la media de días de dicha región y de la medición de todo el país). Por otro lado, la Región Metropolitana Norte es aquella que menor cantidad de días en promedio registra, con 60,4, esto es, 8 días menos en promedio que el resto del país.

Los datos previamente mencionados permiten señalar que la defensa penitenciaria en Chile responde a un modelo de defensa operacional-administrativo, centrado en la gestión de recursos económicos y administrativos, más que uno centrado en el usuario. ${ }^{55}$ De esta manera, se trata de un servicio que no es de calidad, que no cuenta con infraestructura para la defensa, lo que importa, a la luz de la experiencia comparada, falta de privacidad y ausencia de condiciones mínimas para entrevistas. ${ }^{56} \mathrm{La}$ falta de una defensa de calidad se traduce también en que se trata de un servicio poco especializado, usado principalmente por hombres, por lo que poblaciones específicas, como migrantes, minorías sexuales o mujeres no cuentan con atención especializada.

\subsection{Cultura de la Defensa Penitenciaria en Chile}

\footnotetext{
${ }^{54}$ Este plazo según el MAMP debe ser entre 80 y 95 días como máximo. Esta duración se calcula tomando en cuenta el plazo máximo de 20 días entre una petición de requerimiento a la realización de la primera entrevista, luego los 45 días de etapa de estudio, los 15 días adicionales en caso de requerirlo por alguna tramitación, y los 15 días de plazo para realizar la entrevista de cierre. Cabe señalar que el cierre de dicho plazo no necesariamente implica un término exitoso de la defensa penitenciaria, puesto que en muchos casos el "cierre del requerimiento" se da con solo darle cierta información al condenado de su solicitud sin haber terminado su tramitación administrativa o judicial. Por ejemplo, se le puede informar al usuario que se le tramitará un requerimiento de indulto, pero no necesariamente que se le haya otorgado en efecto dicho indulto.

55 CAMPBELL, C. et al. (2015), passim.

${ }^{56}$ GRUNSEIT, A. et al. (2008), passim.
} 


\section{Polít. Crim. Vol. 16, № 31 (Junio 2021), Art. 10, pp. 254-283 [http://politcrim.com/wp-content/uploads/2021/07/Vol16N31A10.pdf]}

Unas de las cuestiones que emergen de inmediato en la cultura de la defensa penal pública es la comprensión de la defensa penitenciaria como una defensa de segundo nivel. Se trata de una labor escasamente reconocida institucionalmente, entendida como un programa piloto más que como una función permanente de la defensoría penal pública. Como suele ocurrir en otras experiencias, la defensa penitenciaria se lleva a cabo en condiciones laborales más precarizadas.$^{57}$ En parte, esto ocurre porque en Chile se trata de un servicio externalizado a oficinas de abogados y sus equipos privados, por lo que entran lógicas de mercado en un espacio que es de responsabilidad estatal. Al respecto, destaca que un $78.3 \%$ de los defensores penitenciarios se mostró en desacuerdo con que la defensa penitenciaria siga bajo el modelo de licitación. De la misma forma, esta encuesta realizada a los defensores penitenciarios de Chile, da cuenta de una sensación de mayor carga laboral, de falta de apoyo por parte de la defensoría penal pública a nivel central y con sueldos más bajos respecto de los defensores de procesos. En efecto, los defensores penitenciarios cuentan con menores garantías en derechos laborales (contratos, pagos, bonos y otros beneficios asociados para todo el equipo de defensa penitenciaria), tienen menor estabilidad laboral en la medida que los procesos de licitaciones ocurren cada 2 años y llevan a cabo su trabajo en peores condiciones pues gran parte de su trabajo se realiza en terreno, en una gran diversidad de lugares, con mayores costos.

Por el hecho de no ser funcionarios públicos, además tienen menores probabilidades de llevar a cabo una carrera funcionaria, profesionalizarse y ser reconocidos por el trabajo que realizan. Este estatus se traduciría en un peor trato por parte de tribunales cuando se comparan con los otros defensores. Finalmente, esta mayor informalidad del trabajo penitenciario hace que el logro de ciertas metas, cuestionados por lo demás por cómo están fijadas, dependa en mayor medida de sus redes, contactos, proactividad.

Por otro lado, el estudio dio cuenta de una cultura institucional que prioriza el conocimiento formal y letrado. En este contexto, es clara la preeminencia del rol del abogado y falta de visibilidad del rol del trabajador social y administrativo. Esto tiene importantes consecuencias prácticas. En efecto, como se ha señalado, la defensa penitenciaria aborda diversas necesidades muchas de las cuales no son propiamente legales y dicen relación con el contexto de privación de libertad y la vinculación con la familia o con instituciones formales. Sin embargo, la prioridad de la mirada letrada y la preponderancia del abogado dentro de los equipos de defensa penitenciaria, relegan a un segundo plano dichas necesidades no propiamente legales.

"hay una brecha de la cual tiene que hacerse cargo desde la defensoría, me refiero a que como servicio hay ser consciente de que hay que redoblar los esfuerzos para hacerle entender a un abogado que falta del ámbito de lo normativo, y ahí el rol del trabajador o la trabajadora social es súper importante (pero) no puede ocurrir es que haya una parcelación absoluta donde el abogado ve todo lo jurídico y el o la trabajadora ve todo lo social, como si fueran cosas distintas, porque este es un ámbito donde justamente las dos cuestiones están súper cruzadas" (Encargado de Defensa Especializada DPP, Panel de expertos/as, 2019).

\footnotetext{
${ }^{57}$ LEMOS, M. H. (2000), passim.
} 
Con esto, la labor penitenciaria se reduce y se ve menoscabada la defensa para un correcto ejercicio de derechos. Un ejemplo palmario de esto es el desconocimiento de los problemas no legales de grupos vulnerables. Así, una gran mayoría de los equipos de defensa penitenciaria declaran no estar preparados para la defensa de grupos vulnerables (madres lactantes, LGTB, migrantes, discapacitados).

A pesar de lo dicho, la cultura de la defensa penitenciaria muestra un bajo nivel de especialización técnica. Los abogados de la defensa penitenciaria enfocan sus conocimientos técnicos en el Reglamento de Establecimientos Penitenciarios, con el fin de introducir modificaciones que permitieran facilitar la reinserción social y contar con un instrumento integral de fácil consulta. Sin embargo, a pesar de ser el principal instructivo que norma el trabajo al interior de los penales, esta es considerada por parte de Gendarmería como un instrumento general y alejado de la realidad, puesto que en la práctica real lo que mandan son las orientaciones técnicas de GENCHI, las circulares internas, y oficios circulares.

\begin{abstract}
"una persona que quiere saber sobre derecho penitenciario tiene que conocer hasta los oficios circulares que saca Gendarmería porque no acaba con lo que dice el 518 (...) el 518 regula a un nivel más macro no más, pero deben meterse mucho más en las orientaciones técnicas, conocer el modelo de intervención que nosotros [Gendarmería] hoy día tenemos... el 518 es una cuestión que no dice nada y lo dice todo, pero al final lo que regula la práctica de la relación de los beneficios principalmente que pueden acceder los internos están bajo la lógica de una solución exenta del oficio circular" (Autoridad Nacional de Gendarmería de Chile, Panel de expertos/as, 2019).
\end{abstract}

Esta falta de especialización técnica sin duda, dice relación con la ausencia de una norma de rango legal que agrupe los derechos, beneficios, modelo intervención y en general la práctica de la ejecución de penas en Chile. De acuerdo a los entrevistados, la ausencia de una instrucción general establecida impacta además en "una falta de formación, porque realmente es difícil formar en Derecho Penitenciario porque no hay una ley común, no hay una legislación, jurisprudencia especializada" (Autoridad Nacional de Gendarmería de Chile, Panel de expertos/as, 2019).

A su vez, la falta de un marco legal que regule el derecho penitenciario solo prolonga otros problemas estructurales del trabajo de defensa penitenciaria, dejándola obligada a adecuarse a la realidad carcelaria y a la lógica de trabajo de Gendarmería. Además de la pobre infraestructura y distribución de espacios, existen también diferencias organizativas entre la institución de defensa y la de custodia que impacta en diversos ámbitos, a saber: en el traspaso de información; en el traslado de internos dentro y fuera del penal; en la difusión de la defensa penitenciaria; o, en el trabajo dentro del Consejo Técnico de Gendarmería, entre otros. Por sobre todo, pareciera que las diferentes maneras de coordinación interna finalmente entorpecen el trabajo de defensa. En palabras de uno de los defensores:

"cuando yo solicito mi forma de visita me dicen que no hay problema, pero me avisan 2 días antes (...) Eso ya demuestra que no hay coordinación por parte de Gendarmería, y me he percatado que cuando voy, a veces no me han citado a la gente, y la gente no sabe. Siendo que hay una lista, entonces yo mismo imprimo mi propia lista, voy y les digo: esta gente yo necesito, y me dicen: es que nunca nos han pasado nada (...) yo de todas 


\section{Polít. Crim. Vol. 16, № 31 (Junio 2021), Art. 10, pp. 254-283 [http://politcrim.com/wp-content/uploads/2021/07/Vol16N31A10.pdf]}

las difusiones que he hecho, Gendarmería no me ha ayudado en eso. Más allá de eso, hay un problema de coordinación porque están acostumbrados simplemente a llamar como de práctica: aquí llegaron los defensores". (CPF Santiago - Entrevista Defensor).

\subsection{Cultura de Gendarmería de Chile}

La cultura de Gendarmería de Chile opera ciertamente como una barrera para la defensa penitenciaria. Esto porque como cuestión de fondo se encuentra una cultura de control, seguridad y dominio sobre lo que ocurre en las cárceles. Esta percepción es compartida por otros operadores del sistema.

"Según su política los presos son de ellos y están acostumbrados a trabajar más solos y les sigue costando entender que hay una institución que ahora les está pidiendo cuentas, como el INDH, como somos nosotros, como los tribunales están más activos gracias a la pega del instituto y a la nuestra" (Entrevista Defensor Penitenciario, Valparaíso).

En este sentido existe la percepción dentro de GENCHI que la defensa penitenciaria constituye una intromisión las labores de los gendarmes. Junto a ello, se encuentra la idea de que los privados de libertad abusan de la defensa penitenciaria y se aprovechan del supuesto desconocimiento de la realidad, lenguaje y prácticas carcelarias:

"uno acá los sanciona porque cometen faltas ¿Ya? y ellos al tiro acuden a la Defensoría Penitenciaria solicitando el apoyo viene la defensoría, piden los antecedentes, enviar al Tribunal... revocan las sanciones que hace Gendarmería, que no se ajustan a derecho... le buscan por todos lados cosa de poder evitar de que el interno sea sancionado (...) nos entorpecen a nosotros como funcionarios." (Entrevista Jefe operativo GENCHI, CP Arica).

En lo central, los miembros de GENCHI dan cuenta de una ambivalencia en sus discursos cuando se trata de la defensa penitenciaria, por un lado, el discurso oficial y políticamente correcto de los mandos altos:

"Una opinión como oficial creo que la defensa penitenciaria lo que tiene es precisamente entregar, reforzar el trabajo que nosotros realizamos en materia técnica, en materia normativa, en materia procedimentales, hace que este trabajo sea más transparente... nos demanda realizar las cosas en una mejora continua y, por su puesto, el gran beneficiado de esto es y son los privados de libertad y también la sociedad en su conjunto" (Jefe módulos, Santiago)

Por el otro, el discurso práctico de quienes tienen contacto directo y diario con la población penal.

"Lo negativo es que mucha gente... ha querido manipular estos servicios para poder querer o intentar debilitar la tarea de la seguridad penal. Que han querido que los allanamientos no sean tan continuos, que la vigilancia no sea tan vigilante, y que se le dé muchas más facilidades para todo. Que el sistema penitenciario se relaje, a tal extremo que ellos quieren o han querido llevar las riendas de la cárcel. Han querido manipular todo sistema de defensa para que el sistema penitenciario de control se debilite" (Jefe operativo, Biobío). 
En efecto, entre quienes trabajan directamente con los privados de libertad, aparece una percepción de la defensa penitenciaria como una amenaza al control sobre las cárceles. El control sobre los privados de libertad y lo que ocurre en la vida diaria de los internos también se observa en la idea de que son ellos, Gendarmería de Chile, quienes conceden "beneficios" a la población penitenciaria. No son derechos consagrados, por tanto, que deben garantizarse. Menos existe la autocomprensión de ser una institución garante de derechos. Así, para la concesión de beneficios un funcionario expresa con alerta:

"Deberían ver de quién se trata, de qué usuario se trata. Porque los perfiles, como te digo, dentro del extracto de filiación sabemos qué persona es... La reincidencia que tienen, no porque estén en un CET [centro de estudio y trabajo] semi-abierto, que hayan llegado acá son... son santas palomas porque están acá" (Entrevista funcionario Gendarmería, CET Arica).

A su vez, la idea de "derechos" es a ratos entendido como un antónimo de disciplina, y por ende, un obstaculizador para el trabajo diario de Gendarmería. Este punto se refleja en ciertas expresiones de los funcionarios que demandan empatía sobre su rol y trabajo. Los gendarmes parecen querer saber ¿De qué lado estás?: del lado de los derechos o del orden. La siguiente reflexión que hace un funcionario ejemplifica lo señalado:

"La sociedad está así: ha habido muchos derechos, y pocas obligaciones [...] Se ha perdido un poco el respeto también. Entonces ellos [la población penal] albergados, cobijándose en el profesionalismo que realiza la Defensoría, ellos instrumentalizan ciertas acciones para poder ser víctimas de cualquier medida de utilización de la fuerza que nosotros tenemos que desarrollar, es decir, no someterse, digamos, al régimen interno" (Jefe operativo, Biobío).

Esta cultura del control debe ser entendida también como una cultura burocrática jerarquizada y con un staff penitenciario que toma decisiones aparentemente técnicas. ${ }^{58} \mathrm{~A}$ pesar de ello, Gendarmería no es una institución técnicamente preparada para la misión institucional que tiene, a saber: "atender, vigilar y contribuir a la reinserción social de las personas que, por resolución de autoridades competentes, fueren detenidas o privadas de libertad" (Artículo 1º , Ley Orgánica Constitucional de Gendarmería de Chile). En efecto, agentes formados principalmente para la custodia de personas deben al mismo tiempo rehabilitar en la cárcel a las personas socialmente muy desaventajadas. Luego, esta falta de preparación técnica, más o menos atribuible a las altas expectativas que se tiene sobre Gendarmería, se desarrolla en una organización compleja, aparentemente especializada, pero, en la práctica, altamente discrecional.

Esta discrecionalidad tiene su fuente en la posición de juez y parte de Gendarmería en tanto dictador de la normativa que regula la vida interna y juez de los alegatos sobre lo que ahí ocurre. Entre otras cosas, la discrecionalidad de Gendarmería fue posible observarla en algunas actuaciones cruciales de la defensa penitenciaria. Una de ellas son las visitas de los equipos penitenciarios. Como se vio, 1 de cada 5 internos no se presenta a dichas visitas y,

${ }^{58}$ WATERS y WATERS (2015), passim; WEBER (1964), passim. 


\section{Polít. Crim. Vol. 16, № 31 (Junio 2021), Art. 10, pp. 254-283 [http://politcrim.com/wp-content/uploads/2021/07/Vol16N31A10.pdf]}

si bien, algunos de ellos no salen por motivos personales, en muchos casos, la frustración de la visita tiene directa relación con arbitrariedades de la administración de GENCHI o el uso de "mozos" 59 que cobran por llevar al interno.

La cultura institucional de Gendarmería se observa también en una opacidad permanente respecto de las razones o fundamentos de sus decisiones. Lo mismo ocurre respecto de otro tipo de información a la que los defensores penitenciarios deben acudir para hacer su trabajo. Mucha de esta información debe realizarse por el sistema general de acceso a la información demorando el trabajo de defensa. En algunos casos, y dependiendo de las relaciones con el alcaide de turno, esta información se entrega de manera directa. Como sea, queda de manifiesto que no existen mecanismos objetivos y eficientes para la entrega de información a los equipos penitenciarios. Un aspecto crítico en este ámbito es la exclusión de los equipos penitenciarios del Consejo Técnico que resuelve las libertades condicionales. Como se ha visto, el otorgamiento de la libertad condicional es una de las tareas centrales de la defensa penitenciaria. Ellos preparan los casos y argumentos a fin de lograr la concesión de la libertad. A pesar de ello, los equipos han sido sistemáticamente excluidos de las decisiones de estos consejos generando vacíos y dudas respecto de la forma en que se toman estas decisiones.

"Ese es un tema bastante complicado porque el alcaide que está ahora, nos dijo
cordialmente nos dijo que no nos iba a invitar al Consejo Técnico, entonces nosotros
postulamos al interno a beneficios intrapenitenciarios, después no tenemos conocimiento
de los resultados de esa postulación, por lo tanto tenemos que solicitarlo a través de
Transparencia y también solicitar los informes (la petición de informe) que le hace el
área técnica de postulación, por Transparencia. Entonces nos llega información 30 días
después y por lo general toda la información tachada, hay casos en que tenemos toda la
información literalmente tachada ni siquiera podemos ver el nombre del interno.
Entonces ahí tenemos que interponer un reclamo, y son 30 días más. Entonces pueden
pasar 2-3 meses perfectamente y no sabemos por qué al interno le rechazaron un
beneficio intrapenitenciario" (Entrevista Defensora Penitenciaria, CDP Santiago Sur).

\subsection{Cultura de privados de libertad}

A pesar de que los principales actores que solicitan requerimientos son las personas condenadas (63,6\% durante el año 2018), y un 11,7\% son sus familiares, a partir de los grupos focales realizados, se observa una falta de conocimiento general de la defensa penitenciaria y sus derechos. Una expresión de esto era la confusión común que presentaban los internos entre abogados de defensa pública general, defensa penitenciaria, y de "Derechos Humanos", referidos más bien a los profesionales del INDH.

Además de la falta de conciencia y empoderamiento legal, el lenguaje y códigos de la cultura carcelaria operan como barreras para la defensa penitenciaria. Ante todo, esta cultura se desarrolla en oposición y con desconfianza frente a las instituciones formales de justicia del Estado. ${ }^{60}$ Siendo esto así, la figura del defensor penitenciario y el trabajador social muchas

\footnotetext{
${ }^{59}$ Los mozos son privados de libertad que prestan servicios menores a la administración de Gendarmería a cambio de pagos informales.

${ }^{60}$ SYKES (2007), passim.
} 
veces es asociado a Gendarmería y rechazado como forma de resolución de conflictos. Cuando un interno busca el apoyo de la defensa penitenciaria debe superar ciertas barreras culturales para aceptar el servicio. Estas barreras muchas veces son concretas y dicen relación con la entrevista entre el interno y los equipos de defensa penitenciaria. En la lógica de la cárcel, la persona debe atravesar pasillos y secciones para tener una reunión que, dada la infraestructura precaria, muchas veces se desarrolla a la vista de todos. En ocasiones, el sólo traslado de los presos por pasillos y secciones rivales importa un riesgo de tal envergadura que frustra la realización de entrevistas.

De esta forma, las expectativas entre los internos y también sus experiencias personales permiten sostener que cualquier forma institucional o estatal para resolver sus necesidades no tendrá resultados. En este sentido, la cárcel es un espacio donde la resolución de conflictos se lleva a cabo por otras vías, no institucionales. Esta cultura de base impide un correcto desarrollo de la defensa penitenciaria, sobretodo, si se trata de un servicio poco conocido y muchas veces asociado a Gendarmería, que es la misma institución fuente de sus necesidades y demandas.

Por otra parte, llama la atención el particular concepto de justicia que perciben los internos, permeada por su vivencia en la realidad penitenciaria. Para ellos, una justicia de calidad no solo debe ser sin discriminación, clara y de buen trato, sino también debe ser oportuna. Lo anterior es interesante pues en un contexto carcelario, ellos reconocen que sus percepciones del tiempo son distintos en comparación a quienes se encuentran en libertad. Para ellos, el tiempo es efectivamente tiempo perdido, y por ende, su apuro y ansiedad por ser escuchados o por recibir justicia implica una sensación de ritmo distinto.

“[...] a veces se demoran un poquito, y porque estamos presos, a veces nos angustiamos porque queremos respuestas rápidas [...] [Yo creo que] uno de los problemas graves somos nosotros mismos, que queremos todo al tiro. Porque el que llega preso, llega con aflicción, que quiere irse luego, y el sistema de Gendarmería es lento" (Antofagasta Focus Group).

Vinculado a este elemento, además de considerar una justicia oportuna, los internos también valoran la dedicación y vocación que observan en ciertos defensores penitenciarios, quienes en un mundo de abandono y temporalidad distinta, hay profesionales que les "abren una puerta de esperanza" (CP Antofagasta, focus group), sensación que contrastan con la vida y relación con los funcionarios penitenciarios. Por ende, el acceso a justicia para los internos se vincula también al derecho de sentir que son importantes y valorados.

Es por lo anterior que, en muchos casos, los internos señalan preferir pagar abogados privados o "de la calle", a esperar la lentitud de la defensa pública. De acuerdo a sus palabras, los abogados de la calle suelen dedicarse más a su caso, actuar más rápido, y mostrar mayor preocupación por ellos y sus familias.

"Tú no vai a hablar como hablai con un defensor penitenciario que con abogado particular. Porque el abogado particular lo podís tratar como un amigo, el penitenciario es como con más respeto [...] El particular viene y me entiende más [...]”. 


\section{Polít. Crim. Vol. 16, № 31 (Junio 2021), Art. 10, pp. 254-283 [http://politcrim.com/wp-content/uploads/2021/07/Vol16N31A10.pdf]}

"Porque un abogado de la calle pelea más por ti, un abogado de acá, creo que le da igual, creo que vienen por la firma no más, bueno aunque no todos son igual” (CP Valparaíso, focus group).

Por último, su concepción de justicia también se ve afectado por otro código cultural que manda en la cárcel: la conducta. Para los internos, en muchos casos la justicia que buscan no es en tribunales, sino es una apelación a su "derecho a los beneficios", tales como a actividades o programas de reinserción, salidas, visitas, entre otros, para hacer más amena su estadía en condena. Por ello, muchos internos expresan que dentro de las cosas que más les importa son las "movidas que hacen con las MB" ("Muy buena"), esto es, cuando los defensores les ayudan a mejorar sus evaluaciones de conducta en caso de que les hayan sancionado por algún incumplimiento en el penal. En este sentido, los internos tienen una cultura común con Gendarmería respecto de la noción de derechos, que no es misma que la de los defensores, porque, en sus palabras, "los pacos viven la cana igual que nosotros" (CPD Santiago Sur). Luego, a pesar de que el concepto de derecho humano ha ido penetrando la cultura de los privados de libertad, en la práctica, los códigos culturales de justicia se enmarcan en la lógica penitenciaria de violencia, conducta y beneficios intrapenitenciarios. Finalmente, vinculado a ese punto, los internos señalan en repetidas ocasiones sobre casos en que Gendarmería aprueba o no el acceso a justicia:

'H: la cana la manda el paco, la abogada me saca en un día pa' la calle, el tribunal me dice en dos días más te vas a cualquier lado y el paco te frena, la cana la manda el paco. El correo llega aquí y tu veni y el paco dice, no aquí mando yo. Por eso te digo que los que ya han hecho meses antes es así. Tu podi, el abogado puede hacerlas todas, el tribunal te apaña, pero después el paco te frena. Aquí tu abogado tiene que ir donde el Alcaide y para que te pesque el Alcaide, estai perdido (CDP Santiago Sur - Focus Group).

\section{Discusión}

\subsection{Cuando no hay derecho}

La defensa penitenciaria en Chile se ha desarrollado tardía y lentamente. Si bien el foco de este artículo no es una evaluación de esta, es posible decir que no ha sido capaz de penetrar la opacidad de Gendarmería, ni superar las lógicas institucionales de la misma Defensoría Penal Pública, Gendarmería y la propia cultura carcelaria.

En gran medida esto es consecuencia de un problema mayor. En efecto, la cárcel en Chile aún es un espacio de desregulación normativa, siendo uno de los pocos países de la región de América Latina que se mantienen sin una legislación especial que regule la ejecución de penas. ${ }^{61} \mathrm{Si}$ bien esto es sabido, este artículo aporta contenidos sobre las consecuencias de contar con un ámbito de la sociedad donde no existen normas legales que regulen los derechos, deberes y la vida de un grupo de personas. Una de estas consecuencias concretas es que las personas privadas de su libertad no son concebidas por el sistema de justicia como titulares de derechos, sino como potenciales merecedores de beneficios. Esta mirada restrictiva de los derechos humanos no se reduce a los beneficios propiamente

\footnotetext{
${ }^{61}$ VENEGAS VALENZUELA (2018), passim.
} 
intrapenitenciarios. También se vincula con los derechos subjetivos de las personas encarceladas. Así, por ejemplo, las visitas de familiares pueden ser severamente restringidas si, a los ojos de la administración de turno de Gendarmería, los internos no han tenido un buen comportamiento. Así como este, existen un conjunto de derechos, por ejemplo, el de comunicarse con el exterior, que son conculcados como formas de castigo.

Desde el rol de los defensores penitenciarios, la desregulación legal de la vida en la cárcel se traduce en que su labor se lleva a cabo de manera desformalizada. En tanto no hay derechos que exigir, tampoco existen mecanismos para concretar dichas demandas por el cumplimiento de derechos, careciendo de canales de comunicación efectivos para ejercer la tutela judicial efectiva. ${ }^{62}$ De esta manera, la defensa penitenciaria se desenvuelve en un contexto sin procedimientos prestablecidos. De aquí que, para estos equipos, tenga prioridad la experticia relacional, por sobre la experticia substantiva. Así como ocurre en otros lugares, el éxito de la defensa depende de la proactividad, contactos, redes y motivación del defensor. ${ }^{63}$ Esto trae problemas serios de justicia en tanto la calidad del servicio es difícilmente estandarizada y altamente dependiente de las características personales de los equipos penitenciarios.

Quizás lo más complejo de la falta de regulación es que, en tanto no hay derecho penitenciario, se amplían los espacios de arbitrariedad. La norma es reemplazada por el criterio de las autoridades del recinto penitenciario. Como es sabido, la ausencia de normas y procedimiento abre paso a mecanismos alternativos de resolución de problemas y corrupción. La cárcel como institución se oscurece aún más. Esto se ve agravado por la inacción de los jueces. La falta de regulación legal de la cárcel es entendida por una mayoría de jueces como una razón para no intervenir en los problemas que se suscitan en el contexto carcelario. El ejemplo más evidente sobre esto dice relación con los conflictos que surgen a partir de los traslados de internos de un recinto a otro. Muchas veces estos traslados se hacen contra la voluntad del interno, con lo que se vulnera el derecho a estar cerca de su familia y cercanos. Los tribunales enfrentados a estos casos han determinado en repetidas ocasiones que se trata de un problema de la administración de Gendarmería y que, como tal, no corresponde al conocimiento de tribunales de justicia.

Esta interpretación de problemas jurídicos de parte de los jueces no hace sino excluir del acceso a la justicia a quienes recurren a ella. En efecto, lo que se hace es perpetuar un círculo altamente vicioso: como no hay derecho, las normas que regulan la vida de los privados de libertad son de carácter administrativo, sin embargo, como las normas son de carácter reglamentario no pueden ser vistas por los jueces, quienes, en su lógica, deciden cuestiones de rango legal. Así, no existe enforcement posible de las normas que regulan la ejecución de la pena; no al menos, si Gendarmería es la única solución para dar cumplimiento a las normas que se impone a sí misma.

\subsection{Superposición de culturas}

\footnotetext{
${ }^{62}$ VENEGAS VALENZUELA (2018), passim.

${ }^{63}$ CLAIR (2018), passim.
} 


\section{Polít. Crim. Vol. 16, No 31 (Junio 2021), Art. 10, pp. 254-283 [http://politcrim.com/wp-content/uploads/2021/07/Vol16N31A10.pdf]}

Como es posible ver, el estudio muestra cómo la defensa penitenciaria se lleva a cabo en un contexto desregulado y complejo en el que intervienen diversas instituciones y culturas. Si bien, existe una gran gama de culturas o creencias institucionales involucradas (por ejemplo, la de las iglesias evangélicas y católica), para los efectos del objeto de esta investigación se han relevado la de la Defensoría Penal Pública, Gendarmería de Chile y la cultura carcelaria. La información cualitativa y cuantitativa aquí mostrada, además de mostrar datos específicos de la defensa penitenciaria, dan cuenta un choque de culturas institucionales.

Los privados de libertad tienen un lenguaje, valores y una cultura que, entre otras cosas, importa formas específicas de resolución de conflictos dentro de la cárcel. Esta cultura tiene como base una desconfianza hacia el personal penitenciario y una firme oposición al sistema de justicia formal. ${ }^{64}$

Por su parte, la cultura institucional de Gendarmería demuestra un choque cultural interno muy fuerte. Mientras que la institución prioriza el control y dureza frente a la población penitenciaria, el personal penitenciario tiene la doble función de velar tanto por la seguridad como por la rehabilitación de los internos. Esta doble función no deja de ser problemática, ya que mientras la primera ha sido asociada a una cultura del daño ${ }^{65}$ o una cultura de "ellos contra nosotros", 66 para describir la pugna entre oficiales de prisión y presos, la función de la rehabilitación enfatiza en cambio, el cuidado y el trato humanitario durante el proceso de custodia. ${ }^{67}$ Esta misma disputa se traduce también en el dilema interno que presentan algunos funcionarios entre qué es lo que deben priorizar: los derechos humanos o la disciplina. En cierta medida, esta dialéctica que se vislumbra al hablar con funcionarios de Gendarmería muestra que tanto ellos como quienes investigan estos temas, terminan inevitablemente por hacerse una de las clásicas preguntas que hacía Becker ${ }^{68}$ al estudiar en cárceles: “¿De qué lado estamos?”: ¿Del lado de funcionarios y de su función del control disciplinario, o del lado de las personas privados de libertad y de sus derechos humanos?

Al mismo tiempo, la cultura de Gendarmería es una cultura burocratizada, que opera como una densa red de interdependencias entre los miembros de la administración penitenciaria. Esta interdependencia dificulta la acción individual. Los miembros se presentan como "representantes burocráticos" que difícilmente quebrarán los códigos de silencio sobre las vulneraciones de derechos al interior de la cárcel. ${ }^{69}$ Desde el punto de vista de la cultura interna, esto es un problema, ya que la burocratización genera estructuras de comando rígidas que impiden el empoderamiento y el cambio en las actitudes de sus miembros. ${ }^{70}$ Esta cultura, con todo, no está exenta de verse influenciada por factores locales, el clima laboral local y la historia particular del ethos de la cárcel en cada contexto. ${ }^{71}$

\footnotetext{
${ }^{64}$ SYKES (2007), passim; SKARBEK (2014), passim.

${ }^{65}$ HANEY (2008), passim.

${ }^{66}$ CREWE et al. (2011), passim.

${ }^{67}$ COYLE (2003), passim.

${ }^{68}$ BECKER (1967), passim.

${ }^{69}$ PRATT (2002), passim; WILSON, D. (2013), passim.

${ }^{70}$ WILSON (2013), passim.

${ }^{71}$ SPARKS et al. (1996), passim.
} 
Finalmente, existen culturas legales que operan dentro de la cárcel. Fiscales, jueces, abogados y defensores públicos desarrollan su trabajo con una mirada especialmente centrada en las normas legales. En dichas culturas predomina una alta valoración por el rol del abogado en desmedro de otras profesiones. Esto, ciertamente tiene como consecuencia la invisibilización de otros agentes del sistema justicia no letrados de manera que, trabajadores sociales, sicólogos o terapeutas, quedan generalmente fuera de las tomas de decisiones relevantes.

En este contexto de superposición y choque de culturas institucionales, la defensa penitenciaria se ve enfrentada a grandes desafíos. En concreto debe desplegarse en una suerte de fricción permanente donde cada institución despliega sus expectativas, prioridades, lenguajes y formas de decisión. Estas “lógicas institucionales”, son mecanismos que vinculan a los individuos con las instituciones y se expresan como rituales que reafirman mitos institucionales y demuestran la posición de sus miembros en el mundo. ${ }^{72}$ En este punto es donde el derecho juega su parte. En efecto, cuando no hay derecho que regule dichas formas de acción institucional, estas entran en competencia. El derecho actúa regulando y conteniendo las expectativas de manera que se generalicen y permitan un consenso en las formas de acción.

\subsection{La urgencia del derecho penitenciario}

Desde la teoría institucional, se espera que las organizaciones que comparten el mismo entorno terminen empleando prácticas similares, de manera que se vuelven "isomórficas" entre ellas. La adopción de estas prácticas se explica por la conformidad de las organizaciones a presiones institucionales manejadas por motivos de legitimidad. Sin embargo, cuando estos entornos son "opacos" y los procesos de transparencia y accountability son escasos, este proceso es de difícil ocurrencia. Con todo, la misma teoría institucional explica que algunos procesos coercitivos y normativos del entorno institucional obligan a que las organizaciones adopten ciertas lógicas, programas y procedimientos. Este proceso se denomina bajo el término isomorfismo coercitivo, cuando los patrones organizacionales son impuestos sobre las organizaciones por una autoridad e isomorfismo normativo, cuando las organizaciones adoptan patrones considerados apropiados en el entorno. En este caso no es del todo claro si la introducción de la defensa penitenciaria y los procedimientos orientados al ejercicio del derecho a defensa, opera como una presión desde la autoridad de Gendarmería o desde el poder judicial (isomorfismo coercitivo), o más bien por la instalación de una cultura de respeto por los derechos humanos e Chile (isomorfismo normativo). ${ }^{73}$

En efecto, los datos surgidos a partir de esta investigación muestran que se han dado ciertos pasos que parecieran mostrar una instalación creciente de una cultura de los derechos humanos respecto de lo que ocurre en las cárceles de Chile, esto es, una suerte de isomorfismo normativo. Sin perjuicio de ello, aún siguen existiendo vulneraciones a los derechos humanos de las personas privadas de libertad. Sobre esto, de acuerdo con Kostova y Roth, ${ }^{74}$ la adopción de una práctica institucional tiene dos componentes, su implementación y su internalización. Mientras la implementación se expresa en comportamientos externos y

\footnotetext{
72 FRIEDLAND y ALFORD (1991), passim; MEYER y ROWAN (1977), passim.

${ }^{73}$ KOSTOVA y ROTH (2002), passim.

${ }^{74}$ KOSTOVA y ROTH (2002), passim.
} 


\section{Polít. Crim. Vol. 16, № 31 (Junio 2021), Art. 10, pp. 254-283 [http://politcrim.com/wp-content/uploads/2021/07/Vol16N31A10.pdf]}

objetivos y en las acciones requeridas para la realización de la práctica, la internalización es el estado en el que los miembros (en este caso, los funcionarios de Gendarmería y la defensoría penal) conciben la práctica como valiosa y desarrollan compromiso con su propiedad simbólica. Así, aun cuando puedan implementarse ciertas prácticas de manera formal por razones de legitimidad institucional, no necesariamente los actores reconocen su sentido o creen realmente en su valor simbólico, lo que hace que se generen más bien “adopciones ceremoniales” de las prácticas.

La teoría institucional sugiere que la adopción ceremonial es probable que resulte de altos niveles de incertidumbre sobre el valor de la práctica (o una creencia de que no es valiosa) combinada con una fuerte presión a adoptarla proveniente del entorno legitimador. Dicha incertidumbre tiene una raíz histórica, ya que el modelo de rehabilitación desarrollado en el periodo de posguerra generó una profunda insatisfacción que llevó a la conclusión de que "nada funciona" y con ello, impulsó el giro punitivo y el consiguiente foco en la función de seguridad de la custodia. ${ }^{75}$

Considerando lo anterior, la práctica de la defensa penitenciaria parece desarrollarse como una "adopción ceremonial". Si esto es así, mientras no exista un proceso de instalación de un derecho penitenciario (isomorfismo coercitivo), la vida de los internos quedará entregada a la discrecionalidad de autoridades administrativas. En un contexto de este tipo la defensa penitenciaria poco podrá hacer para resguardar los derechos de personas en un contexto donde aún no hay derecho.

\footnotetext{
${ }^{75}$ HANNAH-MOFFAT, K. (2013), passim.
} 


\section{Referencias bibliográficas}

BECKER, Howard (1967): “Whose side are we on?”, en: Social Problems (Vol. 14), pp. 239247.

CAMPBELL, Christopher; MOORE, Janet; MAIER, Wesley; GAFFNEY, Mike (2015): "Unnoticed, Untapped, and Underappreciated: Clients' Perceptions of their Public Defenders", en: Behavioral Sciences \& the Law (Vol. 33), pp. 751-770.

CARVACHO, Pablo (2014): Part-time Old Traffickers?: The Imprisoned Population for Drugs Crimes in Chile (Master in science of law dissertation) (Stanford, Stanford University).

CHARMAZ, Kathy C. (2006): "Constructing grounded theory - A practical guide through qualitative analysis" (Londres, Sage Publications).

CLAIR, Matthew (2018): Privilege and Punishment: Unequal Experiences of Criminal Justice (Ph.D. Dissertation, Department of Sociology, Harvard University) (Cambridge, Massachusetts, Harvard University).

COYLE, Andrew (2003): "Humanity in Prison: Questions of Definition and Audit" (Londres, International Centre for Prison Studies).

CRESWELL, John W.; PIANO CLARK, Vicki L. (2007): Designing and Conducting Mixed Methods Research, $2^{\text {a }}$ edición (Londres, Sage Publications).

CREWEW, Ben, LIEBLING, Alison; HULLEY, Susie (2011): "Staff culture, use of authority and prisoner quality of life in public and private sector prisons", en: Australian \& New Zealand Journal of Criminology (Vol. 44 N¹), pp. 94-115.

FEIERMAN, Jessica (2006): "The Power of the Pen: Jailhouse Lawyers, Literacy, and Civic Engagement”, en: Harvard Civil Rights-Civil Liberties Review (Vol. 41), 369-391

FRIEDLAND, Roger; ALFORD, Robert R. (1991): "Bringing society back in: symbols, practices, and institutional contradictions", en Walter W. Powell y Paul J. DiMaggio, The new institutionalism in organizational analysis (Chicago, University of Chicago Press) pp. 232-263.

FUNDACIÓN PAZ CIUDADANA (FPC) (2016): Estudio sobre los niveles de exclusión social en personas privadas de libertad (Santiago, Fundación Paz Ciudadana).

GENCHI (2018): “Compendio Estadístico de Gendarmería de Chile 2018”. Disponible en: https://tinyurl.com/yes9maub [visitado el 09/06/2021].

GENCHI (2019a): "Compendio Estadístico de Gendarmería de Chile 2019". Disponible en: https://tinyurl.com/yfu2q676 [visitado el 09/06/2021].

GENCHI (2019b): "Boletín estadístico N¹22. Diciembre-Enero 2019". Disponible en: https://tinyurl.com/yeowfr93 [visitado el 09/06/2021].

GRUNSEIT, Ann; FORELL, Suzie; MCCARRON, Emily (2008): Taking justice into custody: the legal needs of prisoners (Sydney, Law and Justice Foundation of New South Wales).

HANEY, Craig. (2008): "A culture of Harm, Taming the Dynamics of Cruelty in Supermax prisons", en: Criminal Justice and Behavior, (Vol. $35 \mathrm{~N}^{\circ} 8$ ), pp. 956-984.

HANNAH-MOFFAT, Kelly (2013): "Punishment and Risk" en: SIMON, Jonathan; SPARKS, Richard, The SAGE Handbook of Punishment and Society (Londres, SAGE Publications), pp. 129-151.

INDH (2015): "Estudio de las Condiciones Carcelarias en Chile 2014 - 2015: Seguimiento de Recomendaciones y Cumplimiento de Estándares Internacionales sobre el Derecho 
a la Integridad Personal". Disponible en: https://tinyurl.com/yzdw85a6 [visitado el 09/06/2021].

INDH (2018): "Estudio de las Condiciones Carcelarias en Chile 2016-2017: Diagnóstico del Cumplimiento de Estándares Internacionales sobre el Derecho a la Integridad Personal". Disponible en: https://bibliotecadigital.indh.cl/handle/123456789/1704 [visitado el 09/06/2021].

INTERNATIONAL CENTRE FOR PRISON STUDIES (2019): "World Prison Population List". Disponible en: https://www.prisonstudies.org/country/chile [visitado el 09/06/2021].

KOSTOVA, Tatiana; ROTH, Kendall (2002): “Adoption of an organizational practice by subsidiaries of multinational corporations: Institutional and relational effects", en: Academy of Management (Vol. $45 \mathrm{~N}^{\circ} 1$ ), pp. 215-233.

LEMOS, Margaret H. (2000): "Civil challenges to the use of low-bid contracts for indigent defense", en: NYU Law Review (Vol. 75).

LIBEDINSKY, Sofía (2015): "Rediseño del modelo de defensa penitenciaria para adultos privados de libertad en el nuevo sistema procesal penal" en: Revista Estudios de Políticas Públicas (Vol. N¹), pp. 226-245.

MEYER, John W; ROWAN, Brian (1977): "Institutionalized organizations: Formal structure as myth and ceremony." en: The American Journal of Sociology (Vol. 83 N²), pp. 340-363.

NORTON, Lee; JOHNSON, Jennifer; WOODS, George (2015): "Burnout and Compassion Fatigue: What Lawyers Need to Know", en: UMKC Law Review (Vol. 84), pp 9871002.

PRATT, John (2002): Castigo y civilización (España: Gedisa).

SKARBEK, David (2014): The social order of the underworld: How prison gangs govern the American penal system (Oxford, Oxford University Press).

SPARKS, Richard; BOTTOMS, Anthony; HAY, Will (1996): Prisons and the Problem of Order (Oxford, Oxford Scholarship Online).

SYKES, Gresham M. (2007): The society of captives: A study of a maximum security prison (Princeton, Princeton University Press).

UDP (2015): Informe de Derechos Humanos UDP (Santiago, Universidad Diego Portales).

VENEGAS VALENZUELA, Jaime Alberto (2018): "El defensor penitenciario como fiscalizador de la actividad penitenciaria en el proceso sancionatorio administrativo", en: Revista de la Justicia Penal (N¹2), pp. 229-309.

WATERS, Tony; WATERS, Dagmar (2015): Weber's rationalism and modern society: New translations on politics, bureaucracy, and social stratification (Palgrave Macmillan).

WEBER, Max (1964): Economía y sociedad. Esbozo de sociología comprensiva (Trad. José Medina Echavarría, Juan Roura Parella, Eugenio Ímaz, Eduardo García Máynez y José Ferrater Mora, México D.F., Fondo de Cultura Económica).

WILSON, Dale (2013): Prison management, correctional officer interactions, and organizational structure: an ethnographic approach. Disponible en: https://tinyurl.com/yk5jj5ow [visitado el 09/06/2021]. 